\title{
Executive's Perception on the Outcomes of In-House and Outdoor Training Programmes
}

\author{
Giasuddin Bellary ${ }^{1}$, Pulidindi Venugopal ${ }^{1} \&$ Ganesan P. ${ }^{1}$ \\ ${ }^{1}$ VIT Business School, VIT University, Vellore, Tamil Nadu, India \\ Correspondence: Pulidindi Venugopal, VIT Business School, VIT University, SJT 612 A07, Vellore, Tamil Nadu, \\ India. Tel: 91-416-220-2708; 91-902-555-5062. E-mail: Pulidindivenu@gmail.com; Pulidindi.venu@vit.ac.in
}

\author{
Received: February 12, 2014 Accepted: March 11, 2014 Online Published: March 26, 2014 \\ doi:10.5539/ass.v10n8p222 URL: http://dx.doi.org/10.5539/ass.v10n8p222
}

\begin{abstract}
The purpose of the study is to understand the Executives' perception on the outcomes of in-house and outdoor training programmes. Design/methodology/approach-Data from executives are collected online. The questionnaire was uploaded in the Google docs. Out of 180 executives, 74 executives responded to both questionnaires, which comprised the sample of our study. The collected data was analyzed by mean, standard deviation and MANOVA to know the training outcomes difference between in-house and outdoor training programs. Research Limitations-The executives of the company are based at different Locations, hence it is difficult to go and collect the data in person. Therefore the questionnaire was uploaded in Google docs for response. Practical Implications-It is important to understand the demands of a job and the background of the learners in order to provide training, which meets specific needs. At present both in-house and outdoor trainings are being conducted to executives to persuade their deeds and mind-set in the direction of the Organization. The success of the training program depends on the training outcomes. By studying these factors the company can evaluate the future need of training and development plan and also in selecting the right training programs for executives. Originality and Value-Even though outdoor training is being offered by many companies from last decade research was done in negligible way. This is the first attempt to compare the in-house and outdoor training programs. This type of evaluation is first time in the Indian context as well as in confectionary company.
\end{abstract}

Keywords: confectionary company, executives, perception, training outcomes, training programs

\section{Introduction}

Human evolution itself is a part of history of training; the Stone Age people got themselves trained to fulfill their basic needs. The metal age people had gone one more step further and learnt the art of use of metal and cooking. Thus every page and stage of human civilization will contain training in the backdrop. Even in the monarchial era, the Kings used to send their wards to Gurukul for leaning, which is nothing but a form of residential training (Janakiram, 2012). In the current scenario companies are using training and development as a means to impart professional knowledge, skills, attitudes, habits and other personality traits and facilitate their potential to the maximum possible extent. Training is defined as 'use of means to specific learning, often with the use of techniques that can be identified and continually improved'. It is known as 'a sequence of experience or opportunity designed to modify behavior in order to attain stated objective' (Hasseling, 1974). Majority of the companies are spending their time, money and other resources on training their people. Massive expenses are made to understand the contribution of training in the success of an organization (Bersin, 2003). Effective Training engages the participants to reflect their behaviour and work on adopting their personal and inter personal welfare. Training and development attracts, retains and enhances the skill set and performance of employees by imparting knowledge, changing attitudes and increasing skills. Important methods include In-basket, Case study, Business Games, Role plays, Drama based Training, Sensitivity Training, Behavior Modeling, Coaching, Understudy assignments, Job rotations, Multiple Management Plans, Conferences, Lectures, Programmed instruction etc., (Rao, 2010). Training is incessant and perennial activity hence training evaluation shifted from an individual program to incessant examination of the competence and efficacy of receptiveness in the organization (Davenport, 2006). Executives play vital roles as a leader, project manager and a coach with responsibilities of directing the team to the vision, taking care of operational activities and picking the people and improving the performance through counseling and training (Bob De Contreras, "What does Manger Do). Executives are the indispensable 
resources and priceless Assets of an Organization. They generate creative ideas, translate them into concrete action plans and produce results. When they succeed, they are able to keep everyone in good humor, including shareholders, employees and the general public. They are hailed as "invincible corporate heroes" and even treated as prized possessions of a Country. When they fail, they destroy the scarce corporate resources and make everyone to suffer. The outcomes of managerial actions, thus, are going to be deep, profound and decisive. To get ahead in the race especially in a complex, dynamic and ever-changing world, Executives need to develop their capabilities that go beyond those required by the current job (Rao, 2010). At present companies is conducting both in-house and outdoor trainings the Executives but encouraging the concept of learning outside the Company as the outdoor training programs are latest $\&$ innovative. Outdoor training is not just climbing the rocks indeed it involves more effort, planning and cost to influences one's behavior and attitude towards the Organization. Few will learn how to get along with others, while others learn trust and enhance self-confidence. A difficult decision at work often requires one to view a problem in a different light. Outdoor activities create awareness and a shift from the common pattern of thought that aids in improving lateral problem solving skill.

\subsection{Training and Development before and after Globalization}

Like any other manufacturing companies, Confectionary companies also targeted on how to increase Production and strengthening this activity during the years of 1980-1990. Many training programs were focused towards enhancing the technical skills of the employees. The employees were selected as Apprentice or Trainee Engineers and were given on the job training, later basing on the performance they were absorbed in the regular employment whereas the sales force was trained on basic selling skills. The Companies started giving importance to Health, Safety and Quality at the Manufacturing sources during the end of the year 1990. The Companies changed the strategy and started focusing on development of Human Resources after Globalization effectively. Many Multi-National Companies like Perfetti from Italy, Lotte from Korea, Wrigley's from US identified the potentiality of Confectionery market in India and started opening their shops. There was a paradigm shift in this business and Companies brought in many changes in packaging, design, taste, texture and Quality. Due to stiff competition in the market on aspects like product quality, price and deliverables, HR Department was given importance and the Human Resources were identified as Human Capital. Confectionary companies believed training is the tool to develop the peoples skill and that which can make the Company to sustain and face the competition prevailing. All the cadres in the Companies were imparted training not only to enhance their job related knowledge but also to improve their behavioral skills. Quality has become very important aspect in all the functions of the Company. Innovation was given first place and people were encouraged to come out with new ideas. Many training programs were designed and held to enhance their job skills and soft skills. A separate department called Training and Development was created at the Corporate Offices and separate budget was allocated for training and development. Focus was to develop the employee self-confidence, team spirit, commitment, enhancing quality in all the functions of company. Hence some companies adapted feedback system for the executives for analyzing the training needs and for assessing the outcomes to conduct need based training programs.

\subsection{Need for the Study}

Majority of the companies are organizing many Management Development Programs for their Executives. It has become essential for executives to take self-development as one of the goals. The training programs are aimed to enhance skills as well as to develop creative thinking, problem solving skills, team spirit and behavioral related traits etc., Management development is aimed at preparing executives for future jobs with the organization or at solving organization wide problems concerning, acquiring or sharpening capabilities required in performing various tasks and functions associated with their present or expected future roles. Both in-house and outdoor training programs are conducted to executives by spending huge budgets with an expected outcome. The Impact of training cannot be measured directly but change in attitude and behavior that occurs as a result of training can be measured. The assessment will be made after each training session by the management, to know the effectiveness of training given to the executives. The study aims in identifying the significance difference of executives on in house and outdoor training programs impact/influence on enhancing the skills development, self-development and behavioral development. This assessment of training outcomes helps to finalize the future training programs. The $s t u d y$ is conducted on the Executives of Confectionary Company's. In this context, an attempt is made to study the objective namely, to identify the differences in executives' perception towards the in house and outdoor training programs in enhancing their skills and to decide the future training program on the basis of views and opinions of Executives. 


\section{Literature Review}

\subsection{Outcomes and Impacts of Training}

The study concentrates on the learner's objective, organization's objective, time duration, cost effectiveness and hand to hand help of the co-workers need to be considered in designing and deciding the training (Day \& Peters, 1990). The training programs are perceived as more successful as it focuses more on improving the job related skills and also the return on investment is more visible in formal training programs hence they are given priority (McDowall \& Saunders, 2010). Training exercises should be tied to business objectives with the classes customized to concentrate on the job-specific skills required to meet objectives, The entire program should also be geared to words career development and provide for employee feedback (Armstrong et al., 1996). It has been found that the trainings have had an overall positive effect on the employees. The employees have gained more knowledge and have definitely benefited from the exposure that trainings provide. Moreover, their managers' sheer interest in the training has also been beneficial (Soltani \& Liao, 2009). There should be a relation between business plan and development program, content relevance, relevance to individual needs and facilitate transfer of training (Graham \& Mihal, 1986). Training is a major factor in creating a Competency Advantage; Quality training goes hand in hand to establish excellence in the Organization work culture (Motwani, 1994). The participants' favorable action on knowledge, attitude and skill is an indication for their favorable reaction to banseke outdoor training programs (Yin et al., 2001). As per the researcher the improvement in performance shown by the trainee after attending the training is an opportunity to assess the impact of outdoor management development program and estimate the return on investment (Donnison, 1995). The paper aims in evaluating the outcomes of various outdoor management development programs. The researcher categorized the articles basing on certain criterion, out of which one criterion includes personal/self-development, management/leadership skills development, team building development and development of learning autonomy empowerment (Jones \& Oswick, 1993). The researcher used Kirkpatrick (1976) four levels of training outcomes; reactions, learning, behaviour and results for measuring the return on investment of outdoor experiential training (Williams et al., 2003). The researcher deals with transformation, continuous cycle of action and reflection, dealing with the issues relevant to the learner, learning with others and in challenging and supportive (The Forum Corporation, 1995).

\subsection{Important Factors in Making Trainings Successful}

Trainer performance and training process have the strongest impact on learning and usefulness. The remaining factors (Training Environment, Training goals, Training content, and Training material) also affect learning and usefulness (at a satisfactory level)-(Diamontidis et al., 2012). Determination of training needs is an important factor in training, so the trainer should ensure that the job roles are properly structured and properly resourced before deciding the training (Chaston, 1993). The needs of Employer or individual employee should determine the Training provision. In the Jargon of the Trade, we need a "Learner-Centered training process", which automatically leads to efficiency in Training, lower the cost and increase motivation (Johnson, 1989). (Johnson, 1989, Vol.31, ISS. 3). Factors like trainers' capabilities (clarity), venue of the program, practical application, food served, and communication skill of trainer were identified as most successful factors of training (Ghosh, Joshi, Satyawadi, Mukherjee, \& Ranjan, 2011). Some factors like voluntary attendance, reputation of the training, design of the training, relatedness of training for personal needs, career and job inspires to attend a training programme (Aziz \& Ahmad, 2011).

\subsection{Types of Training}

Activities involving more physical extortion and brain storming may provide opportunity to learn more managerial skills (Chapman \& Lumsdon, 1983). It deals with how both mental physical exercises helped in enhancing their skills like; communication, adapting to situations, team work, taking responsibility working to deadline and identifying their own leadership style (Pollitt, 2011). The learning from outdoor training helps the ordinary people to sustain in changed environment and develop the skill to become successful (Smith et al., 1997). Outdoor trainings improve individual and group behaviours. It encourages participants towards self/own learning. It also focuses how virtual reality activities develop insights in individuals and groups (Wagner et al., 1994). Drama based training has been found to be most effective when participants engage themselves to reflect on their own behaviour and work on adapting their behaviour for personal and inter-personal welfare (Swales, 2010). The author opined that the outdoor training be supposed to outcome personal development, team development and management development (Bank, 1983).

Thus, basing on the previous studies, the following hypotheses are developed to know the executives' perception basing on the outcomes of training programmes.

$H_{1}$ : There is no significance difference in the executives' perception on skill development. 
$\mathrm{H}_{2}$ : There is no significance difference in the executives' perception on team building development.

$H_{3}$ : There is no significance difference in the executives' perception on training relatedness.

\section{Methodology}

The main purpose of the study is to bring out the perception difference on in-house and outdoor training on the executive's performance in a confectionary company and thus results in applying descriptive research approach. As no earlier studies found in confectionary companies, hence the study is conducted in confectionary company. The questionnaire was designed with 20 items which captures the effects of training and items were identified from various earlier studies. The survey was conducted in the months of October-2012 to March-1013 in Andhra Pradesh. A pilot study was conducted initially to check ambiguities and communication errors with a limited sample. The structured questionnaire was administered through online. Out of 180 executives, 74 executives responded to both questionnaires, which comprised the sample of our study. Subjects were asked the questions related to perception of executives: "in-house training increases self-awareness, self-confidence, inter-personal skills, etc.?" They were also asked to rate "outdoor training increases self-awareness, self-confidence etc.?" on a seven point Likert scale (1-lowerst and 7-highest). Factor analysis is used to find out the inexplicable or unexplained factors that influence the co-variance among multiple observations. Exploratory Factor analysis (EFA) is adapted to find out the training outcome constructs for both the in house and outdoor training. These items were tested through item-to-total correlation and all items' secure are above 0.30 with reliability scores of 0.946 and 0.961 for in house and outdoor training respectively. To group the training attributes/outcomes outdoor training responses are taken into consideration because the high alpha value and number of dimensions related to training outcome constructs.

\section{Analysis}

The suggestion given by Hair et al., (2006, p. 114) is followed in this study to interpret the factors/outcomes derived through the factor analysis (Principal Component Analysis). The suggestion is that items which has higher factor loading is considered as an important and has greater effect on the naming the factor and/or selected label to signifies the name of a factor. Thus, the research will examine all the significant variables for a particular fact and, placing greater emphasis on those variables with higher loadings, will attempt to assign a name or label to a factor that accurately reflects the variables loading on that factor (Hair et al., 2009, p. 155).

The factor analysis results for the training (Table 1) attributes/outcomes explain KMO is.868 and Bartlett's test values are-Chi-Square (1.584E3), df (190) and sig. (.000). The exploratory factor analysis results brought three factors which account 72.90 variance. Nine items out of twenty loaded together and it named as Skill Development factor which has the factor mean of 5.84 with 30.5 total variance explainer. The item included under this factor are relatedness to career, decision making, inter personal skills, persuasiveness, taking initiative, relatedness to personal needs, negation, self-confidence and proactive thinking.

The second factor namely team building development is with 9 variables namely developing others, strategy with action, drive to learn, analytical skills, fostering collaborations, leading team, driving innovations, delivering actions and self-awareness. The mean score of factor is 5.8 with percent of variance of 28.65 .

Relatedness to job and practices application converts together and named as training relatedness. This factor accounted 13.75 percent variance with mean score of 6.19 .

Table 1. Outcomes from the training provided

\begin{tabular}{lllll}
\hline Factor Name/Outcomes & Factor Load & Factor Mean & Factor Variance & (TVE) \% of Variance \\
\hline Skill Development & & $\mathbf{5 . 8 4}$ & $\mathbf{. 6 2 4}$ & $\mathbf{3 0 . 5}$ \\
Relatedness to career & .795 & & & \\
Decision making & .794 & & \\
Inter personal skills & .780 & & \\
Persuasiveness & .747 & & \\
Taking initiative & .682 & & \\
Relatedness to personal needs & .651 & .607 & & \\
Negotiation & .589 & .559 & & \\
Self-confidence & & & \\
Proactive thinking & & & \\
\hline
\end{tabular}




\begin{tabular}{lllll}
\hline Factor Name/Outcomes & Factor Load & Factor Mean & Factor Variance & (TVE) \% of Variance \\
\hline Team Building Development & & $\mathbf{5 . 8 0}$ & $\mathbf{. 6 2 8}$ & $\mathbf{2 8 . 6 5}$ \\
Developing others & .877 & & & \\
Strategy with action & .802 & & & \\
Drive to learn & .693 & & & \\
Analytical skills & .686 & & & \\
Fostering collaborations & .661 & & & \\
Leading team & .647 & & & $\mathbf{1 3 . 7 5}$ \\
Driving innovations & .643 & & & \\
Delivering Actions & .612 & & $\mathbf{. 5 6 9}$ & \\
Self-awareness & .595 & & & \\
Training Relatedness & & $\mathbf{6 . 1 9}$ & & \\
Relatedness to job & .961 & & & \\
Practical application & .964 & & & \\
\hline
\end{tabular}

Extraction Method: Principal Component Analysis.

Rotation Method: Varimax with Kaiser Normalization.

Table 2. Multivariate tests for comparison of executives' perception on outcomes of in house training and outdoor training

\begin{tabular}{|c|c|c|c|c|c|c|c|}
\hline Effect & Value & \multicolumn{2}{|l|}{$\mathbf{F}$} & Hypothesis df & \multicolumn{2}{|c|}{ Error df } & Sig. \\
\hline Pillai's Trace & .324 & \multicolumn{2}{|c|}{$23.053^{\mathrm{a}}$} & 3.000 & \multicolumn{2}{|c|}{144.000} & .000 \\
\hline Wilks' Lambda & .676 & \multicolumn{2}{|c|}{$23.053^{\mathrm{a}}$} & 3.000 & \multicolumn{2}{|c|}{144.000} & .000 \\
\hline Hotelling's Trace & .480 & \multicolumn{2}{|c|}{$23.053^{\mathrm{a}}$} & 3.000 & \multicolumn{2}{|c|}{144.000} & .000 \\
\hline Roy's Largest Root & .480 & \multicolumn{2}{|c|}{$23.053^{\mathrm{a}}$} & 3.000 & \multicolumn{2}{|c|}{144.000} & .000 \\
\hline \multirow[t]{2}{*}{ Training Outcomes } & \multicolumn{2}{|c|}{ Type of Training } & Mean & Std. Deviation & $\mathbf{N}$ & $\mathbf{F}$ & Sig. \\
\hline & \multicolumn{2}{|c|}{ In_House_Trg } & 5.4535 & .67267 & 74 & & \\
\hline \multirow[t]{3}{*}{ Skill Development } & \multicolumn{2}{|c|}{ Out_Door_Trg } & 5.8559 & .76644 & 74 & 11.523 & .001 \\
\hline & \multicolumn{2}{|l|}{ Total } & 5.6547 & .74644 & \multicolumn{2}{|c|}{148} & \\
\hline & \multicolumn{2}{|c|}{ In_House_Trg } & 5.4790 & .76294 & \multicolumn{2}{|l|}{74} & \\
\hline \multirow[t]{3}{*}{ Team Build Development } & \multicolumn{2}{|c|}{ Out_Door_Trg } & 5.8033 & .79244 & 74 & 6.433 & .012 \\
\hline & \multicolumn{2}{|l|}{ Total } & 5.6411 & .79207 & \multicolumn{2}{|c|}{148} & \\
\hline & \multicolumn{2}{|c|}{ In_House_Trg } & 5.2432 & .63161 & \multicolumn{2}{|l|}{74} & \\
\hline \multirow[t]{2}{*}{ Training Relatedness } & \multicolumn{2}{|c|}{ Out_Door_Trg } & 6.1959 & .75316 & 74 & 69.517 & .000 \\
\hline & \multicolumn{2}{|l|}{ Total } & 5.7196 & .84158 & \multicolumn{2}{|c|}{148} & \\
\hline
\end{tabular}

Source: Survey report

The MANOVA and Univariate F-test with descriptive statistics for the total sample of 74 executives of confectionary company is presented in Table 1 and Table 2. The results of MANOVA's four tests, especially Wilks' Lambda (Wilks' $\Lambda=0.676, \mathrm{~F}=23.053^{\mathrm{a}}(\mathrm{df}=3$ ), sig. $=0.000)$ supports there is a significant difference in executives perception on training outcomes: skill development, self-development and training need relatedness of in-house and outdoor training programmes.

It is noted that on skill development of training outcomes there is no significant difference between in house and outdoor training methods. The $\mathrm{f}$ value $(\mathrm{f}=11.523, \mathrm{p}=0.001)$ supported by the mean values of in house training (5.45) and outdoor training (5.86). With team building outcome the $f$ value (6.43), $p$ value (0.001) indicates there is difference between two types of training and the mean values are 5.47 for in house training and 5.80 for outdoor training. Lastly with respect to training relatedness the f value supports there is high degree of difference between the two training types with mean values of 5.24 for in house training and 6.19 for outdoor training. Therefore the hypotheses $\mathrm{H}_{1}, \mathrm{H}_{2}$ and $\mathrm{H}_{3}$ are not accepted. 


\section{Discussion}

It is to be noted from the factors/outcomes of training is that the executives look for a training, whether it can be in-house and/or outdoor training it necessarily focus on the developing various types of skills which will be useful for them to learn and use in their day-to-day business roles through which they can improve their overall performance. Outdoor programmes can provide an intense and relevant learning experience (Jones, 1993). The executives derive the benefit of implementing the practical problem solving skill in their current role. They can enhance the decision making skill by relating to the issues learnt during the trainings and can also improve relations with colleagues, peers and subordinates by using the learned skills during the training. This finding is in line with the observation of David Pollit (2007), that is, the outdoor training facilitates to understand each other, to know skills, experience as teams usually working virtually. The executives can learn the skills in how to enhance persuasiveness in resolving day to day job related issues. Managers need new skills for managing change in uncertainty, can the outdoors be used to shape up managers and help them to sharpen their skills (Bank, 2007). The practical management games in which executives participate will give opportunity to exhibit their initiative in resolving problems more meaningful. Many industries claim real benefit from using well-conceived outdoor activities for leadership training, team building, improving communication, etc. (Bank, 2007). It improves completing their desire to reach their personal career goals. The training enhances negotiation skills which help them in having meaningful solutions and it boosts the confidence in completing the tasks taken up them.

On the comparison between in-house and outdoor training methods with respect to training outcomes, the perception of executives clearly emphasizes that the outdoor training provides tremendous scope for learning of various skills, team building and training relatedness compared to that of in-house training. Outdoor training programmes encourage the individual to experience personal development in terms of self-awareness and recognition of strengths and weaknesses in others. It also provides an opportunity to practice appropriate managerial skills (Chapman et al., 1983). The reasons attributes are, when the executives are outside from their work place, which will make them comfort and think-out-of-box on the issue given to them for the discussion during the training period. The trainers are normally from the outside in both training methods, however, sometimes there will be nil participation of in-house trainers when the outdoor training take place that results in openness and involvement of the trainees.

\section{Conclusion}

The present study emphasizes the executives' perception regarding the outcomes from the training programme provided by the organization through in-house and outdoor methods. The outcomes identified through the application of factor analysis and named as-skill development, team building development and training relatedness These three factors/outcomes of the training programme accounted two-third of variance. The MANOVA results report there is a significant difference in the executives' perception towards the training outcome constructs of both in-house and outdoor training programmes. The executives' opined that outdoor training is developing skills, team building and training relatedness when compared in-house training. Outdoor trainings are real and more enjoyable and help to remember for a longtime to get better results (Yeadon, 1994). Hence it is better to conduct more outdoor training programmes than in house training programmes.

\section{Managerial Implications}

It is important to understand the demands of a job and the background of the learners in order to provide training, which meets specific needs. At present both in-house and outdoor trainings are being conducted to the executives in Confectionery Company's to persuade their deeds and mind-set in the direction of the Organization. The success of the training program depends on the training outcomes. By studying these factors the company can evaluate the future need of training and development plan and also in selecting the right training programs for their executives. Further research on this shall benefit the Confectionery Companies in attracting the best talent and retaining them, which helps in increasing the Productivity and Performance in making existing products and to introduce New Products with enhanced Quality, Taste, and Texture with reduced cost and offer at low price than the Competitors in the Market.

\section{References}

Armstrong, D. G., \& Kleiner, B. H. (1996). Transferring Learning to the workplace. Management Development Review, 9(1), 8-12. http://dx.doi.org/10.1108/09622519610181702

Aziz, S. F. A., \& Ahmad, S. (2011). Stimulating training motivation using the right training characteristic. Industrial and Commercial Training, 43(1), 53-61. http://dx.doi.org/10.1108/00197851111098171 
Bank, J. (1983). Outdoor Development: A New Perspective in Management Education. Leadership \& Organization Development Journal, 4(3), 1-44. http://dx.doi.org/10.1108/eb053533

Chapman, A., \& Lumsdon, C. A. (1983). Outdoor Development Training: A New Tool for Management. Leadership \& Organization Development Journal, 4(4), 28-31. http://dx.doi.org/10.1108/eb053538

Chaston, I. (1993). Managing for Total Training Quality. Journal of European Industrial Training, 17(5). http://dx.doi.org/10.1108/EUM0000000000235

Coetzer, A., Redmond, J., \& Sharafizad, J. (2012). Decision making regarding access to training and development in medium-sized enterprises: An exploratory study using the Critical Incident Technique. European Journal of Training and Development, 36(4), 426-447. http://dx.doi.org/10.1108/03090591211220348

Day, A., \& Peters, J. (1990). The Role of the Architect in Training and Development. Management Decision, 28(8). http://dx.doi.org/10.1108/EUM0000000000065

Diamantidis, A. D., Prodromos, D., \& Chatzoglou. (2012). Evaluation of formal training programmes in Greek organizations. European Journal of Training and Development, 36(9), 888-910. http://dx.doi.org/10.1108/03090591211280955

Donnison, P. (1995). OMD put to the test. Management Development Review, 8(5), 35-37. http://dx.doi.org/10.1108/09622519510772004

Ghosh, P., Joshi, J. P., Satyawadi, R., Mukherjee, U., \& Ranjan, R. (2011). Evaluating effectiveness of a training programme with trainee reaction. Industrial and Commercial Training, 43(4), 247-255. http://dx.doi.org/10.1108/00197851111137861

Gibson, E. (1983). The Value of Using Training Intelligence Services: A broad assessment of the training scene. Industrial and Commercial Training, 15(9), 278-279. http://dx.doi.org/10.1108/eb003955

Graham, J. K., \& Mihal, W. L. (1986). Guidelines for Designing Management Development Programmes. Journal of Management Development, 5(5), 57-64. http://dx.doi.org/10.1108/eb051630

Jones, P. J., \& Oswick, C. (1993). Outcomes of Outdoor Management Development: Articles of Faith? Journal of European Industrial Training, 17(3). http://dx.doi.org/10.1108/03090599310026337

Malik, A., \& Nilakant, V. (2011). Extending the "size matters" debate: Drivers of training in three business process outsourcing SMEs in India. Management Research Review, 34(1), 111-132.

McDowall, A., \& Saunders, M. N. K. (2010). UK managers' conceptions of employees training and development. Journal of European Industrial Training, 34(7), 609-630. http://dx.doi.org/10.1108/03090591011070752

McEvoy, G. M., \& Buller, P. F. (1997). The power of outdoor management development. Journal of Management Development, 16(3), 208-217. http://dx.doi.org/10.1108/02621719710164355

Motwani, J. G., Frahm, M. L., \& Kathawala, Y. (1994). Achieving a Competitive Advantage through Quality Training. Training for Quality, 2, 35-40. http://dx.doi.org/10.1108/09684879410056229

Smith, D., \& Vaughan, S. (1997). The outdoors as an environment for learning and change management. Industrial and Commercial Training, 29(1), 26-30. http://dx.doi.org/10.1108/00197859710156858

Soltani, E., \& Liao, Y. Y. (2010). Training interventions: Fulfilling managerial ends or proliferating invaluable means for employees: Some evidence from Iran. European Business Review, 22(2), 128-152. http://dx.doi.org/10.1108/09555341011023498

Swales, R. (2010). How to get the best out of drama based training. Industrial and Commercial Training, 42(5), 260-264. http://dx.doi.org/10.1108/00197851011057555

The Forum Corporation. (1995). Training-the key to business success: How to make the effort worthwhile. Managing Service Quality, 5(2), 44-47. http://dx.doi.org/10.1108/09604529510796368

Wagner, R. J., \& Campbell, J. (1994). Outdoor-based Experiential Training: Improving Transfer of Training Using Virtual Reality. Journal of Management Development, 13(7), 4-11. http://dx.doi.org/10.1108/02621719410063350

Williams, S. D., Graham, T. S., \& Baker, B. (2003). Evaluating outdoor experiential training for leadership and team building. Journal of Management Development, 22(1), 45-59. http://dx.doi.org/10.1108/02621710310454851 
Wilson, J. P., \& Western, S. (2001). Performance appraisal: An obstacle to training and development? Career Development International, 6(2), 93-100. http://dx.doi.org/10.1108/13620430110383401

Yin, L. Y., Saundi, T., Ahmad, S., \& Samah, B. A. (n. d.). The Effectiveness of Outdoor Training Programme at Banseke Human Resource Development Centre.

\section{Copyrights}

Copyright for this article is retained by the author(s), with first publication rights granted to the journal.

This is an open-access article distributed under the terms and conditions of the Creative Commons Attribution license (http://creativecommons.org/licenses/by/3.0/). 